NASA Technical Memorandum 102118

AIAA-89-2837

\title{
Performance Characterization and Transient Investigation of Multipropellant Resistojets
}

\author{
(BASA-TV-102118) EERFCBHANCE \\ CHARACTERIZATIOA AND TRANSIFAT IUVESTIGATION \\ $N 89-2 \leq 2 \varepsilon 3$ \\ CF ELTIEROEELLANT EESISTCJETS \\ Lewis Researcb Certer) $21 \mathrm{~F}$ \\ IEASA. \\ CSCL $21 \mathrm{H}$

$\begin{array}{ll}\text { Unclas } \\ \mathrm{H} 2 / 20 & 0217720\end{array}$

Edward P. Braunscheidel

Lewis Research Center

Cleveland, Ohio

Prepared for the

25th Joint Propulsion Conference

cosponsored by the AIAA, ASME, SAE, and ASEE

Monterey, California, July 10-12, 1989

\section{NRSA}




\title{
PERFORMANCE CHARACTERIZATION AND TRANSIENT INVESTIGATION OF
}

MULTIPROPELLANT RESISTOJETS

\author{
Edward P. Braunscheidel \\ National Aeronautics and Space Administration \\ Lewis Research Center \\ Cleveland, Ohio 44135
}

\begin{abstract}
SUMMARY
The multipropellant resistojet thruster design initially was characterized for performance in a vacuum tank using argon, carbon dioxide, nitrogen, and hydrogen, with gas inlet pressures ranging from 13.7 to $310 \mathrm{kPa}$ (2 to $45 \mathrm{psia}$ ) over a heat exchanger temperature range of ambient to $1200^{\circ} \mathrm{C}\left(2200^{\circ} \mathrm{F}\right)$. Specific impulse, the measure of performance, had values ranging from 120 to $600 \mathrm{sec}$ for argon and hydrogen respectively, with a constant heat exchanger temperature of $1200^{\circ} \mathrm{C}\left(2200^{\circ} \mathrm{F}\right)$. When operated under ambient conditions typical specific impulse values obtained for argon and hydrogen ranged from 55 to $290 \mathrm{sec}$, respectively. Performance measured with several mixtures of argon and nitrogen showed no significant deviation from predictions obtained by directly weighting the argon and nitrogen individual performance results. Another aspect of the program investigating transient behavior, showed responses depended heavily on the start-up scenario used. Steady state heater temperatures were achieved in 20 to $75 \mathrm{~min}$ for argon, and in 10 to $90 \mathrm{~min}$ for hydrogen. Steady state specific impulses were achieved in 25 to 60 , and 20 to 60 min respectively.
\end{abstract}

\section{INTRODUCTION}

The goal of this program was to establish a database for multipropellant resistojet thrusters that spans their operating envelopes. Thrusters were characterized for their steady state and transient behaviors on individual and mixtures of gases.

Resistojets are planned to be used on board Space Station Freedom for safe, effective disposal of waste fluids in an environmentally acceptable manner and as an auxiliary propulsion system to perform supplemental altitude reboost (ref. 1). By using on board waste fluids with resistojets, the potential exists for significant reductions in the amount of propellant resupply required for the main propulsion system. Resistojets can provide benefits over their long life at a modest initial system cost, and have built-in low maintenance requirements.

These simple devices provide high exhaust velocities by passing fluids through an electrically heated heat exchanger and expansion through a nozzle. Typical fluids are: hydrogen, hydrazine, carbon dioxide, nitrogen, air, helium, water, methane, and argon. For a Freedom application, high performance was traded for long life due to uncertainty in propellant types, quantities, and contaminates that may be experienced. The multipropellant thruster considered here was designed to operate on both reducing and oxidizing gases run through the same thruster. Based on these conditions a design temperature of

Copyright : 1989 by the American Institute of Aeronatics and Astronautics. Inc. No copyright is asserted in the Linited States under Title 17. U.S. Code. The U.S. Govern ment has a royalty-free license to exercise all rights under the copyright clamed herein for Govermmental purposes.

All other rights are rescred by the copyright owner. 
$1400{ }^{\circ} \mathrm{C}$ was selected. When testing began this temperature was lowered to $1200{ }^{\circ} \mathrm{C}$ providing an added safety factor for achieving the desired life.

Resistojets have been used on a relatively large number of flight experiments and operational propulsion systems from 1965 to 1971 . Tables I and II show a compilation of the history and operating conditions for these systems based on references 2 to 5 . In support of the Manned Orbital Research Laboratory (MORL), there was a large technical program for resistojets throughout the 1960 's and into the early 1970's. Work was discontinued when the MORL program was terminated. In the early 1980's hydrazine resistojet propulsion systems were used for north/south stationkeeping of Intelstat and RCA communication spacecraft (refs. 3 and 4 ).

The engineering model multipropellant resistojet characterized in this program was hardware built by Technion Incorporated, and the Rocketdyne Division of Rockwell International, for NASA Lewis Research Center in support of the Space Station Advanced Development Program. The objective of the program was to provide an effective and reliable manner to dispose of waste fluids while providing impulse for Freedom (ref. 6). The design's primary concerns were to insure material compatibility with a large variety of waste gases, and obtain an operational life of at least $10000 \mathrm{hr}$. Five resistojet thrusters were fabricated and delivered to NASA Lewis. Preliminary performance characterization of the first resistojet was conducted at Lewis with a variety of propeliants at two thrust levels for each of two input power levels (ref. 7 ). This thruster contained an incomplete heat exchanger due to difficulties encountered during assembly.

Since the first engineering model resistojet was tested, four additional thrusters of a similar design to the first but with complete heat exchangers have been delivered. Performance data for these additional thrusters was obtained for argon, carbon dioxide, nitrogen, and hydrogen individually, with various mixture ratios of argon and nitrogen included. The performance data was acquired using the original design, called thruster $A$, and with a thruster that contained enhancements which was designated thruster $B$. Transient data using thruster $B$ was obtained with argon and hydrogen for two temperatures with two start-up scenarios. These two gases were chosen based on their wide dispersion of thermodynamic properties, and are expected to span the possible waste gas constituents.

\section{TEST ARTICLE AND APPARATUS}

Resistojets are comprised of a number of generic components. These consist of a heat source which is an electrical resistance heater, pressure vessel, nozzle, thermal shielding, and possibly a heat exchanger if the heater is not immersed directly in the gas flow. Due to material compatibility concerns the engineering model resistojet incorporated a heat exchanger to provide a barrier between the gas and the heater element. This decision was based on the belief that the heating element would be the life limiting component, and thus, precautions should be taken to insure its survival. The design details of the engineering model multipropellant resistojet are described in reference 8 ; a summary is included here. In this design the heat exchanger and pressure vessel were incorporated together. The material used for the heat exchanger; nozzle, and heater were constructed from grain stabilized platinum due to its 
ability to provide long term, high temperature compatibility with a wide variety of oxidizing and reducing fluids. The platinum contains less than 1 percent zirconium oxide dispersant as a grain stabilizer to minimize grain growth, which occurs when materials are held at high temperatures for extended periods of time (ref. 9). Excessive grain growth leads to distortion and weakening of components, which is a concern for the pressure vessel of a resistojet.

The resistojet shown in figure 1 , consists of a cylindrical heat exchanger surrounded by a sheathed coiled electrical resistance heater element. The heat exchanger external configuration is cylindrical with helical, screw type grooves on the downstream half. These grooves are semicircular in crosssection and are designed to mate with the heater element. The internal geometry of the heat exchanger provides a gas passage between the outside of a hollow center cylinder and the inner heat exchanger wall. This wall has 36 equally spaced axial channels broached into it through which the propellant is forced (fig. 2). The pressure vessel walls were designed to resist stress rupture for at least $10000 \mathrm{hr}$ at $1400^{\circ} \mathrm{C}\left(2550^{\circ} \mathrm{F}\right)$, and $310 \mathrm{kPa}$ (45 psia), with approximately 10000 cycles.

The heater consists of a $1.6 \mathrm{~mm}(0.063 \mathrm{in.})$ diameter platinum-rhodium center conductor surrounded by a layer of magnesium oxide insulator, both which are contained in a grain stabilized platinum sheath. The heater is folded in half, then wound in a helical configuration which allows both power leads to be located at the upstream end of the thruster. By wrapping the heater in this double helix configuration the radiated magnetic field is effectively compensated for, thus requiring minimal shielding (ref. 10). The heater and heat exchanger are designed to be screwed together, enabling proper location of the heater and heat exchanger relative to each other. An added benefit is greater surface contact area for improved diffusion bonding and increased conduction paths to the heat exchanger. The heater is then wrapped with a grain stabilized platinum ribbon to maintain a hoop type pressure on the heater coil until heater and heat exchanger can be diffusion bonded.

The upstream end of the pressure vessel contains a flange which incorporates the propellant inlet tube. The downstream end of the pressure vessel is terminated at the nozzle. This nozzle has a convergence area ratio of 132:1 with a $1.016 \mathrm{~mm}(0.040 \mathrm{in}$.) diameter throat. The expansion section consists of a $25^{\circ}$ half-angle conical nozzle which has an area ratio of 225:1. A trumpet extension is then added onto the conical section resulting in an area ratio of 2500:1. The nozzle design is based on reasoning that the thrust for a nozzle operating strictly in a vacuum should be optimized for that regime. When the viscous effects of a laminar boundary layer are taken into account, the resulting displacement thickness can be extremely large relative to the size of the nozzle. The trumpet's design attempted to minimize the boundary layers effect of reducing the nozzle expansion area ratio. The trumpet's area ratio was designed to diverge at the same rate that the boundary layer was growing, resulting in no net area ratio reduction of the conical section. This shape also provides structural support to the internal assembly by attaching directly to the outer shell.

The pressure vessel components are joined by large surface area diffusion bonds which serve as stress bearing joints. These bonds are backed by electron beam welds to insure a positive gas seal. The diffusion bonds are used in high 
temperature, high stress locations since this bond does not destroy the grain stabilized properties, as does electron beam welding.

The radiation shields which surround the heater coil and heat exchanger consist of ten layers of foil separated by a small diameter wire. These wires were used to maintain the desired spacing while introducing minimal conduction paths to the outer shell. The three layers of shields closest to the heat exchanger are made of platinum due to the high temperatures, and the remaining shields are nickel. Thruster $B$ has 10 additional radiation shields with the 10 closest to the thruster being platinum and the remaining 10 being nickel. The support shroud is made of Inconel, and serves to protect the heat exchanger and shield pack while providing a mounting point for the thruster. This shroud contains a series of small vent holes in the downstream end to provide for evacuation of the radiation shield pack. In case of a pressure vessel leak, these vents will help to insure that the gases are accelerated away from the Freedom.

\section{TEST STAND AND FACILITY}

For purposes of testing the resistojet was mounted horizontally on a thrust measurement stand developed and built at the NASA Lewis (fig. 3). This device relates the horizontal displacement of the thruster to the generated thrust, by using a linear variable differential transformer (ref. 11). The stand is calibrated by applying known forces to the stand and recording the resulting displacement. The entire thrust stand is water cooled to help eliminate thermal drift. Windage effects on the thruster were eliminated by the use of a windage shield. The shield was a thin stainless steel sheet approximately one-tenth of a square meter, attached to a stationary part of the thrust stand. The shield is located parallel to the nozzle exit plane of the thruster. The thruster fires through a hole in the center of this shield. The thrust stand is able to accommodate up to three thermocouples which were of the chromelalumel type. They were attached to the thruster shell near the nozzle, at the midsection, and near the power leads as illustrated in figure 1 . The wiring for these thermocouples is such that they do not impede the freedom of the flexures in the thrust stand.

The test stand was mated to a $4.6 \mathrm{~m}$ (15 ft) diameter by $19 \mathrm{~m}$ (62 ft) long vacuum tank via a port similar to a bell jar. This bell jar allowed the experiment to be isolated when needed from the main tank which is maintained under constant vacuum. The bell jar is evacuated to approximately 0.1 torr, then the valve is opened to the main tank. This tank has twenty $0.8 \mathrm{~m}(2.6 \mathrm{ft})$ diameter oil diffusion pumps, four lobe type blowers and four displacement pumps (ref. 12). The tank's capable of cryo-pumping with liquid nitrogen cooled baffles which was utilized when carbon dioxide was tested. The ultimate pressure of the tank is 10-7 torr ( 1 torr $=1 \mathrm{~mm}$ of mercury).

\section{THRUSTER PERFORMANCE CHARACTERIZATION}

\section{Procedure}

In developing the test plan for the performance characterization tests, consideration was given to how this thruster would be controlled in flight. 
Likely methods would be to control the inlet operating pressure and/or the heater temperature. The inlet pressure dictates the thrust level, and the temperature establishes the specific impulse $\left(I_{S p}\right)$. The next step was to determine the operating envelope of the thruster. The engineering model resistojet was designed with a pressure vessel limit of $310 \mathrm{kPa}$ (45 psia) (ref. 8), establishing the upper limit for inlet pressure. The lower pressure limit was set at $13.7 \mathrm{kPa}$ (2 psia), which was the lowest pressure for obtaining accurate measurements. Intermediate pressures of $68.9,137.8$ and $206.8 \mathrm{kPa}(10,20$ and $30 \mathrm{psial}$ were included to effectively span the operating envelope. The operating temperature of $1200{ }^{\circ} \mathrm{C}\left(2200^{\circ} \mathrm{F}\right)$ was used as the upper temperature limit. The lower limit was ambient conditions. Intermediate temperatures of 500 and $900{ }^{\circ} \mathrm{C}$ ( 9.30 and $1650^{\circ} \mathrm{F}$ ) were included to cover the operating envelope.

Based on studies to determine the most likely candidates for waste gases on the Freedom, argon, nitrogen, and carbon dioxide were shown to represent over 70 percent of the total mass of waste gases (ref. 13). These gases were run individually, with argon and nitrogen run in mixtures of $1: 3,1: 1$, and $3: 1$ based on mass. Mixtures were tested since they more closely simulate actual waste gas conditions that resistojets will experience on the Freedom. Hydrogen was tested to determine the effects of using a gas which deviates significantly from the others in terms of thermal properties.

For steady state conditions each test point was run twice to ensure accuracy when time permitted. The thruster was operated until it had reached its heater temperature and Isp equilibriums, then data was recorded. In most cases this resulted in the thruster reaching its overall thermal equilibrium.

Experimental parameters that were measured included inlet pressure at the point just before the gas entered the thruster, current and voltage, thrust, mass flow rate, tank pressure, and thruster shell temperatures. All instruments were calibrated before the testing began, the thrust stand was calibrated at the beginning and end of each test day. The tests were conducted with a dc power supply due to its ease of control and allowed direct monitoring of the heater resistance from which heater temperature is calculated.

During testing the tank was maintained at as low a pressure as possible to ensure accuracy. At the lower flow rates tested a tank pressure in the $10^{-4}$ torr regime was maintained during approximately 50 percent of the testing. When flow rates were increased so that the tank pressure rose above the $10^{-4}$ torr regime, the diffusion pumps had to be turned off to insure that no diffusion pump oil back streamed into the tank. With the diffusion pumps off, the tank pressure was at all times less than $4 \times 10^{-2}$ torr. The information obtained with the diffusion pumps on is an accurate measurement of performance that will be seen in space. The data taken at the higher pressures had to be corrected.

\section{Thrust Correction}

It has been demonstrated (ref. 14) that at tank pressures above $10^{-3}$ torr, the expansion process of gas flow in a nozzle is affected. The normal procedure is to correct the thrust by adding a tank pressure multiplied by a nozzle exit area term to the measured thrust. This type of correction works well for unheated gases in a conical nozzle, but is unacceptable for heated flow. This 
type of correction was not directly applicable since we were dealing with heated flows and a trumpet nozzle. An attempt was made to find an effective area ratio for this trumpet nozzle to establish a method by which to correct the tank pressure effect on the thrust (ref. 14).

The results showed that the effective area needed for correction varied significantly with operating conditions of the thruster. Test data for nitrogen indicated that the thrust was reduced by approximately 12 percent for an increase in tank pressure of $10^{-4}$ to $10^{-2}$ torr. To directly apply this correction factor to the current investigation did not seem appropriate since the operating scenarios were not identical. Since $I_{s p}$ is dependent upon the gas temperature, this parameter was used to obtain a conservative correction factor for the thrust. By definition, if the $I_{S p}$ and mass flow are known, the thrust can be calculated. Some test data was generated for most cases under desired conditions (tank pressure $<10^{-3}$ torr) that established what we will call the "ideal" I $S P$. This is the Isp which should be obtained in a space environment. The ideal Isp was then compared with the measured I $I_{s p}$ obtained for the same operating conditions with the diffusion pumps off (higher tank pressure). A corrected thrust is obtained by calculating what thrust is needed at the measured mass flow rate to obtain the ideal $I_{s p}$. This correction factor was calculated for each applicable point for a given temperature. The variation in magnitude of the correction factor was small enough to allowed the use of an average correction factor for each temperature and gas. This type of correction factor may be thruster specific, and represents a conservative correction factor when compared with other existing data.

\section{Performance Results for Single Gases}

The thruster demonstrated good repeatability of delivered thrust, mass flow and required power input for all conditions tested. Both thrusters tested performed similarly, regardless of the ten additional radiation shields that thruster $B$ had in its configuration. This could have been caused by a compression of the radiation shields during assembly. This seems plausible because the additional radiation shields were incorporated without changing the dimensions of the outer shell.

Table III presents a summary of the test data obtained in this study for nitrogen. Points to notice are the 13.7 and $68.9 \mathrm{kPa}$ test cases. An overall measurement of thruster performance is its $I_{s p}$ which is dependent upon the gas temperature. Performance measurements for the $13.7 \mathrm{kPa}$ inlet condition case resulted in much worse performance than all other conditions. The higher temperature $68.9 \mathrm{kPa}$ conditions also exhibited poor Isp compared to the other data. The overall efficiencies (defined later in this section) were also found to be much lower than the bulk of the data. Whether these phenomenas can be attributed to poor heat transfer or viscous losses in the nozzle, the $13.7 \mathrm{kPa}$ data will not be included since a deviation from the norm is not so drastic.

Figure 4 presents the corrected thrust versus power input for the entire test matrix. No correction factor was needed for carbon dioxide since the tank pressure was always maintained below $10^{-3}$ torr by utilizing the nitrogen cryo-pumping capability. An effect of decreasing thrust with increasing power/ 
temperature can be seen. The average thrust is indicated for each of the inlet pressures tested. At temperatures above $300^{\circ} \mathrm{C}$, the thrust levels are within $0.030 \mathrm{~N}(0.006 \mathrm{lbf})$ of the average. This suggests that the thrust level is highly dependent upon the inlet presssure, and fairly independent of the gas type and its temperature. Figure 5 compares the $I_{s p}$ to the estimated gas temperature for all the gases over the entire test matrix, with the exception of the $13.7 \mathrm{kPa}$ inlet condition. The dependency upon operating temperature is strongly evident. Performance appears to be independent of operating pressure relative to the $I_{s p}$. The curves for this plot were generated from a square root of temperature divided by the molecular weight ratio, then multiplied by the necessary constant. This method to predict performance is very simple and provides a good correlation with the test data. Table IV presents typical $I_{S p}$ values and the empirical correlation factor associated with each of the individual gases. I $\mathrm{sp}$ values for temperatures not tested can be found by simple interpolation.

Thermal losses represent a significant problem for this type of thruster. The engineering model resistojet attempted to minimize such losses with the use of radiation shields. The effectiveness of these shields is reflected in the overall thruster efficiencies. Overall thruster efficiency accounts for all energy losses that can be assigned to an electrical thruster including wasted electrical power, loss of thrust due to dispersion of the flow in the nozzle, and thermal losses (ref. 15). The thrusters overall efficiency was evaluated based on its ability to convert electrical energy into kinetic energy. This is defined as the energy exiting the thruster relative to energy input. The energy delivered by the thruster is the kinetic energy, called Pjet here, being the power in the jet.

$$
P_{\text {jet }}=1 / 2 \mathrm{mu}^{2}
$$

Where $m$ is the mass and $u$ is the gas velocity. This expression can be converted into parameters that are easily obtained from experiment to

$$
P_{j e t}=F\left(I_{s p}\right) g / 2
$$

Where $F$ is the thrust and $g$ is the universal gravitational constant. The energy input to the thruster is electrical, and the enthalpy of the incoming gas is taken as being at the inlet to the thruster. The expressions used for energy input is:

Power input

$$
P_{i n}=I E+n h
$$

Where $I$ and $E$ are current and voltage, $n$ is the mass flow rate, and $h$ is the enthalpy of the gas at ambient conditions.

Therefore the expression for overall thruster efficiency is:

$$
P_{j e t} / P_{i n}=F\left(I_{s p}\right) g / 2(I E+n h)
$$

As expected the efficiency is a maximum at ambient flow conditions and decreases with increasing temperature. Figures 6 and 7 present thruster efficiency versus thrust-to-power ratio $(F / P)$. Figure 6 illustrates this relationship with nitrogen for the entire test matrix. The temperature of each point 
is indicated and increases from right-to-left. The curve approaches its maximum efficiency asymptotically, being the condition of zero power which is on the order of 90 percent. Figure 7 combines the efficiencies for all the gases. This plot shows that the gases with the exception of hydrogen behave similarly for F/P ratios of less than 1 , with behavior so alike that only very small differences can be seen. For $F / P$ ratios of less than 1 , the heater temperatures were greater than $900{ }^{\circ} \mathrm{C}$. As the temperature was reduced below $900{ }^{\circ} \mathrm{C}$, the $F / P$ increased and the similarity in efficiencies between the gases became less pronounced. Under these conditions the overall efficiency between the gases is arranged in ascending order by decreasing molecular weight. They all approach the 90 percent efficiency zone for ambient temperature, zero power conditions. Hydrogen demonstrated the highest efficiency by a significant factor at all conditions except for cold flow where it was comparable to the other gases.

Information gathered here on the overall thruster efficiency and the performance measured by specific impulse, offer insight into how the thruster will likely respond for any set of operating conditions. This thruster exhibited poor efficiency and $I_{S p}$ for all gases run with the $13.7 \mathrm{kPa}$ (2 psia) inlet condition, and the $68.9 \mathrm{kPa}(10 \mathrm{psia})$ heated flow cases. For all cases, the efficiency decreases with increasing temperature, while the $I_{s p}$ is increasing. Some of the benefits of operating at a high temperature include better impulse which translates into less resupply for the main propulsion system. This also extends the operational life of the main system. The negative aspect of this mode is a lower power usage efficiency. A tradeoff is required to determine the optimum operating point that maximizes delivered impulse and minimizes power losses.

\section{Performance Results for Mixed Gases}

Once the individual gases were characterized, the focus was turned to how mixtures of these gases would perform. At the time this study was initiated argon and nitrogen represented the majority of waste gases on a mass basis, and could be combined easily and safely. The same test matrix and procedure was used for the mixtures that was developed for the individual gases. Due to time constraints, the $13.7 \mathrm{kPa}$ case was omitted and multiple runs of test points were not always performed. These changes should not introduce any significant variance based on experience and insight achieved from previous testing.

The gases were tested in mixture ratios based on mass fractions of 25,50 and 75 percent argon, with nitrogen being used to make up the balance. It was assumed that no reactions took place which is reasonable given the inertness of argon. This assumption will have to be closely scrutinized when these thrusters are used with more realistic gas mixtures which are expected to be encountered in space flight applications. Figure 8 is a plot of the $I_{s p}$ versus gas temperature for argon and nitrogen as they performed individually and their response in the three mixture ratios. A predicted performance curve is indicated by the center dashed line, which was arrived at by simply averaging the argon and nitrogen Isp's achieved individually. This prediction agreed well with the 50 percent argon mixture data. A good approximation for mixtures of 25 and 75 percent argon can be determined by taking a ratio of the gas mass fraction to the performance of the individual gases. The resulta of running argon and nitrogen mixtures demonstrates that at least simple mixtures of gases will operate stably, and performance can be predicted. 


\section{TRANSIENT OPERATION}

\section{Procedure}

When consideration is given to start-up characteristics of a resistojet, the transient behavior is important. Such information is needed in developing resistojet operating strategies and in determining duty cycles. To shorten the test time of running all the gases in a transient mode, a decision was made to test representative gases whose thermodynamic properties would span the range of properties that the resistojet would be expected to handle. Argon and hydrogen were chosen as the two candidate test fluids because they most closely satisfy this requirement. Gases were run at pressures of $68.9,137.8$ and $206.8 \mathrm{kPa}(10,20$ and $30 \mathrm{psia})$, nearly spanning the planned range of operating pressures. The temperature ranges were ambient to $760^{\circ} \mathrm{C}\left(1400^{\circ} \mathrm{F}\right)$ and ambient to $1200^{\circ} \mathrm{C}\left(2200^{\circ} \mathrm{F}\right)$. The temperature of the thruster was established from an empirical heater resistance versus temperature relationship, and monitored by measurements from three thermocouples located on the shell as previously described. The thruster designated for testing was thruster $B$.

Two start up scenarios were used so that the heating characteristics would be better defined. One was fast or "maximum preheat" method, the other a slow or "minimum preheat" method. The steady state operating conditions which had previously been established have associated set point values for power which were used as bench marks during testing. The maximum preheat method means that power was initiated without flow at a maximum current level of $30 \mathrm{~A}$ until the heater temperature had risen to approximately 90 percent of the desired set point. Gas flow was then initiated and controlled at a constant inlet pressure; current was reduced to the set point value. Starting the flow before the temperature set point is reached will guard against temperature overshoot that could damage the thruster. The second start-up scenario was slow or minimum preheat method, which began with a current level of $30 \mathrm{~A}$ until the temperature had risen to approximately $300^{\circ} \mathrm{C}$ which should be sufficient to safely accelerate the gases with no condensation. Gas flow was then initiated and controlled to a constant inlet pressure, current was reduced to the set point value and the testing proceeds to steady state conditions. The heater element has a maximum current limit of $50 \mathrm{~A}$, but facility limitations set the $30 \mathrm{~A}$ maximum current level for these tests.

The heater temperature and the $I_{S p}$ were the quantities used to track the conditions of the thruster during start-up. The focus was the time required for the above quantities to achieve 90 and 98 percent of their steady state values.

\section{Transient Results}

Table $V$ is a compilation of the transient test data with some of the problems encountered as noted. The control errors were due to inadequate response times during initial tests. Once the behavior of the thruster was established, these problems were overcome. Unfortunately the facility had become dedicated to other experiments resulting in limited test data. An automatic controller with a simple temperature feedback loop would have solved 90 percent of problems experienced. 
The thruster behavior varied significantly with amount of preheat as shown in figures 9 to 12. Plotted are typical response times for the two propellants tested. Heater temperature start-up histories in figures 9 and 10 show the differences between the maximum and minimum preheat scenarios. During preheat the heater temperature exhibited a linear transient until flow was initiated. No significant temperature drop was observed with flow initiation, a temperature plateau of 2 to 10 min was normally experienced.

The temperature response using hydrogen, illustrated in figure 9 for the $1200{ }^{\circ} \mathrm{C}$ maximum preheat test condition, resulted in a linear temperature gradient of $100^{\circ} / \mathrm{min}$ until gas initiation. The gradient was then reduced to $3 \% / \mathrm{min}$ and prevailed until steady state was reached. It should be noted that the actual temperature gradient approached the steady state condition asymptotically for all cases. The $760{ }^{\circ} \mathrm{C}$ maximum preheat condition responded with gradients which were not discernibly different from the $1200{ }^{\circ} \mathrm{C}$ case. For the $1200{ }^{\circ} \mathrm{C}$ minimum preheat case, the temperature gradient was linear at $90^{\circ} / \mathrm{min}$ until gas initiation when the gradient was reduced to $18^{\circ} / \mathrm{min}$ until the $25 \mathrm{~min}$ elapsed time point was reached, the gradient was reduced to $8 \% / \mathrm{min}$ to the $50 \mathrm{~min}$ point when the gradient was finally reduced to $5 \% / \mathrm{min}$ until steady state was achieved. The $760{ }^{\circ} \mathrm{C}$ minimum preheat begins with the same initial gradients $90^{\circ}$ and $18^{\circ} / \mathrm{min}$ to the $20 \mathrm{~min}$ point when the gradient was reduced to $2.5^{\circ} / \mathrm{min}$, until steady state was achieved.

Typical temperature response for the heater using argon as the working fluid, shown in figure 10 for the $1200{ }^{\circ} \mathrm{C}$ maximum preheat, begins with a 1 inear increase of $80^{\circ} / \mathrm{min}$ for the first $10 \mathrm{~min}$ after which gas flow was initiated. The gradient reduced to about $8 \% / \mathrm{min}$ until the $35 \mathrm{~min}$ point and was reduced to a rate of $3 \% \mathrm{~min}$ until steady state was reached. The $760{ }^{\circ} \mathrm{C}$ maximum preheat case began with the same initial gradient for the first $6 \mathrm{~min}$, then changes to a $3.5^{\circ} / \mathrm{min}$ positive gradient until steady state was achieved. For the $1200{ }^{\circ} \mathrm{C}$ minimum preheat case, the initial gradient was again $80^{\circ} / \mathrm{min}$ for the first $3 \mathrm{~min}$, then changes to $22 \%$ min until the $18 \mathrm{~min}$ point was reached when the gradient was reduced again to $13^{\circ} / \mathrm{min}$ to the $44 \mathrm{~min}$ point and was finally reduced to $6^{\circ} / \mathrm{min}$ until steady state was achieved. The $760{ }^{\circ} \mathrm{C}$ minimum preheat had the same initial gradient, changes to $9^{\circ} / \mathrm{min}$ to the $36 \mathrm{~min}$ point, then was decreased to $4 \%$ min until steady state was reached. The overall response rate for the two different temperatures level were quite similar; the lower temperature condition exhibited slightly faster response characteristics.

The achievement of the 90 percent point for the slow heat method with argon ranged from 45 to $65 \mathrm{~min}$. For the limited data obtained with hydrogen, the 90 percent point was achieved in 55 to $65 \mathrm{~min}$. The 98 percent point took 60 to $75 \mathrm{~min}$ for argon, and 80 to $90 \mathrm{~min}$ for hydrogen.

The Isp for the maximum preheat method for all cases fell within a narrow range of 8 to $15 \mathrm{~min}$ to reach the 90 percent point. This development means that even for gases which have extremely different thermodynamic properties, they will achieve 90 percent of their steady state performance in roughly $12 \mathrm{~min}$ if this preheat method is used. The minimum preheat method reached the 90 percent $I_{S p}$ point in 25 to $42 \mathrm{~min}$ for argon and in 30 to $40 \mathrm{~min}$ for hydrogen. The longest transients were at the lowest inlet pressures.

$I_{S p}$ is influenced by the square root of the gas temperature as previously discussed. This translates into I sp transients which should mimic 
the heater temperature transient response rates. Figures 11 and 12 indicate this behavior even though they are not as smooth as the heater temperature curves. This can be attributed to a slight mismatch between desired flow rate and actual flow rate delivered during the test sequence. The one major difference between the heater and impulse curves is that the steady state $I_{s p}$ is achieved more quickly than is the steady state heater temperature. One possible explanation is that the gas responds to the hottest section of the heat exchanger, while the temperature measurement for the heater is an overall average which has a slower response. The results showed that the maximum preheat method achieved steady state conditions in roughly half the time it took the minimum preheat method. The tests as performed did not yield a significant difference in response based on what gas is used.

\section{CONCLUDING REMARKS}

Multipropellant resistojets are proposed to be on-board Space Station Freedom to provide an effective and beneficial manner to dispose of waste or excess fluids. As the design and analysis of propulsion and fluid systems proceed, detailed information of the components is required. The data generated, and reported here, fulfills this requirement by greatly expanding the limited database of multipropellant resistojet thrusters. Enough data now exists between this and previous reports to confidently predict how the thruster will perform during steady state operation anywhere in its extensive operating envelope. Transient data can be utilized to determine if response times are acceptable or require further modification. The only gray area that still remains is how this thruster will perform with various mixtures. The limited mixture data acquired in this study offers insights, but as is often the case, additional testing is always beneficial.

\section{ACKNOWLEDGMENTS}

Contributions to this report by R. Slutz, D. Sokolowski, and R. Tacina of NASA Lewis Research Center are gratefully acknowledged.

\section{REFERENCES}

1. Tacina, R.R., "Conceptual Design and Integration of a Space Station Resistojet Propulsion Assembly," AIAA Paper 87-1860, June 1987. (NASA TM-89847).

2. Greco, R.V., Bliss, J.R., Murch, C.K., Clark, K.E., and Kelly, A.J., "Resistojet and Plasma Propulsion System Technology," AIAA Paper 72-1124, Nov. 1972.

3. Dressler, G.A., Morningstar, R.E., Sackheim, R.L., Fritz, D.E., and Kelso, R., "Flight Qualification of the Augmented Electrothermal Hydrazine Thruster," AIAA Paper 81-1410, July 1981.

4. McKevitt, F.X., "Design and Development Approach for the Augmented Catalytic Thruster (ACT)," AIAA Paper 83-1255, June 1983. 
5. Mirtich, M.J., "Resistojet Propulsion for Large Spacecraft Systems, " NASA TM-83489, 1982.

6. Jones, R.E., "Space Station Propulsion: The Advanced Development Program at Lewis," AIAA Paper 85-1154, July 1985 (NASA TM-86999).

7. Morren, W.E., Hay, S.S., and Haag, T.W., "Preliminary Performance Characterizations of an Engineering Model Multipropellant Resistojet for Space Station Application," Journal of Propulsion and Power, Vol. 5, No. 2, Mar.-Apr. 1989, pp. 197-203.

8. Shephard, C.B., McKevitt, F.X., and Finden, L.E., "Multipropellant Resistojet," NASA CR-182199, Oct. 1988.

9. Morren, W.E. and Sovey, J.S., "2000-Hour Cyclic Endurance Test of a Laboratory Model Multipropellant Resistojet," AIAA Paper 87-0993, May 1987 (NASA TM-89854).

10. BriehT, D., "Magnetic Emissions Testing of the Space Station Engineering Model Resistojet," NASA TM-100788, 1988.

11. Haag, T.W. and Curran, F.M., "Arcjet Starting Reliability: A Multistart Test on Hydrogen/Nitrogen Mixtures," AIAA Paper 87-1061, May 1987 (NASA TM-89867).

12. Finke, R.C., Holmes, A.D., and Keller, T.A., "Space Environment Facility for Electric Propulsion Systems Research," NASA TN-D-2774, 1965.

13. Peterson, T.T., "Space Station Fluid Inventories of the Integrated Waste Fluids and Integrated Water Systems," NASA Lewis Research Center PIR-191, Mar. 1987.

14. Manzella, D.H., et al., "An Experimental Investigation of the Effect of Test-Cell Pressure on the Performance of Resistojets," AIAA Paper 88-3286, July 1988.

15. Sutton, G.P., and Ross, D.M., Rocket Propulsion Elements, Fourth Edition, John Wi ley and Sons, Inc., 1976, pp. 467-468. 
TABLE I. - FLIGHT HISTORY OF RESISTOJET THRUSTERS

\begin{tabular}{|c|c|c|c|c|c|}
\hline Spacecraft & $\begin{array}{l}\text { First } \\
\text { flight }\end{array}$ & $\begin{array}{l}\text { Total } \\
\text { flights }\end{array}$ & Propel Tant & Manufacturer & Function \\
\hline $\begin{array}{l}\text { Vela } \\
\text { Navy } \\
\text { satellite } \\
\text { ATS-A, C } \\
\text { Advanced } \\
\text { Vela } \\
\text { ATS-D, E } \\
\text { Navy } \\
\text { satellite } \\
\text { Navy } \\
\text { satellite } \\
\text { INTELSAT V } \\
\text { Flights (1 to 4) } \\
\text { RCA SATCOM G }\end{array}$ & $\begin{array}{l}1965 \\
1965 \\
1966 \\
1967 \\
1968 \\
1971 \\
1971 \\
1981 \\
1983\end{array}$ & $\begin{array}{l}2 \\
4 \\
2 \\
4\end{array}$ & $\begin{array}{l}\text { Nitrogen } \\
\text { Ammonia } \\
\text { Ammonia } \\
\text { Nitrogen } \\
\text { Ammonia } \\
\text { Ammonia } \\
\text { Hydrazine } \\
\text { Hydrazine } \\
\text { Hydrazine }\end{array}$ & $\begin{array}{l}\text { TRW } \\
\text { GE } \\
\text { AVCO } \\
\text { TRW } \\
\text { AVCO } \\
\text { AVCO } \\
\text { AVCO } \\
\text { TRW } \\
\text { RRC }\end{array}$ & $\begin{array}{l}\text { Orbit adjustment } \\
\text { Attitude control } \\
\text { and orbit control } \\
\text { Experiment } \\
\text { Orbit adjust/ } \\
\text { attitude control } \\
\text { Attitude control } \\
\text { Operational system } \\
\text { Experiment } \\
\text { North/South } \\
\text { stationkeeping } \\
\text { North/South } \\
\text { stationkeeping }\end{array}$ \\
\hline
\end{tabular}

TABLE II. - OPERATING CHARACTERISTICS

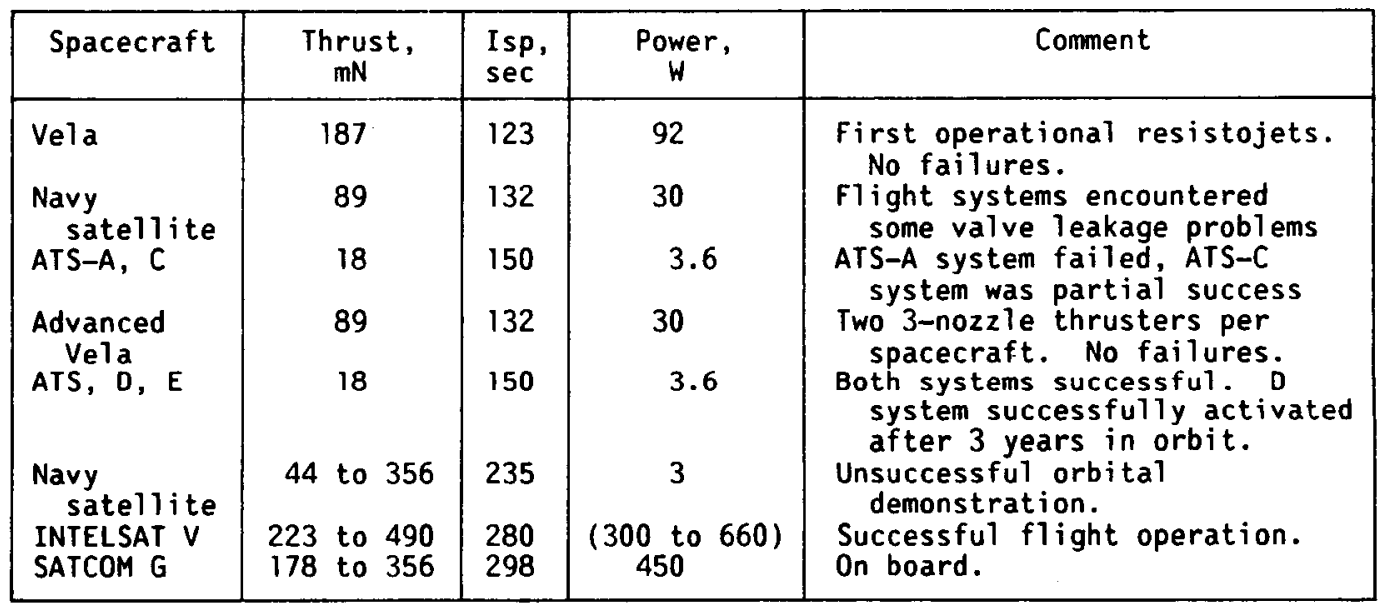




\begin{tabular}{|c|c|}
\hline 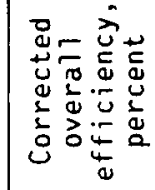 & 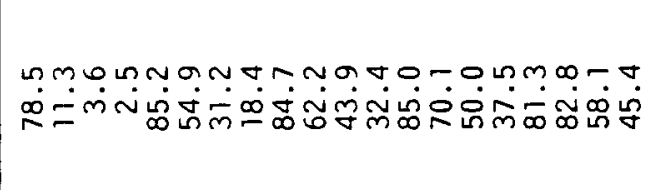 \\
\hline 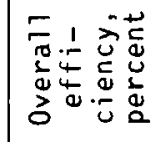 & 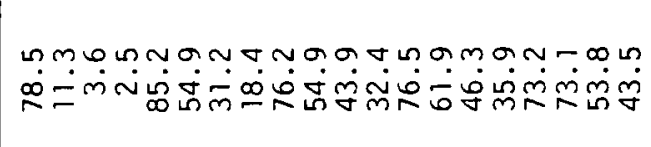 \\
\hline 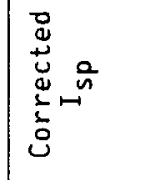 & 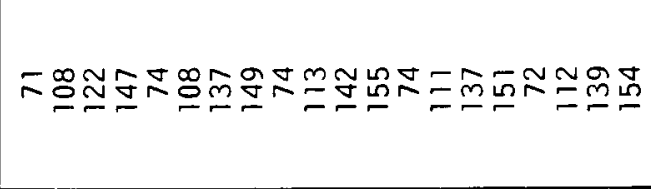 \\
\hline 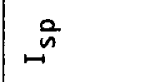 & 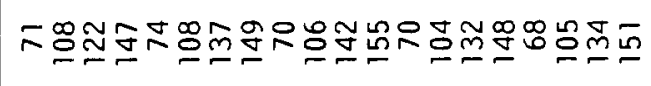 \\
\hline 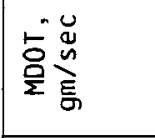 & 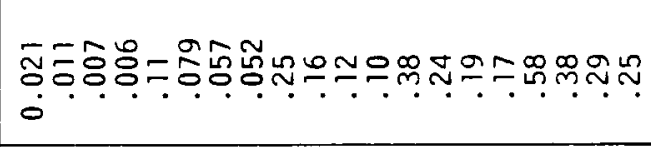 \\
\hline 焉 & 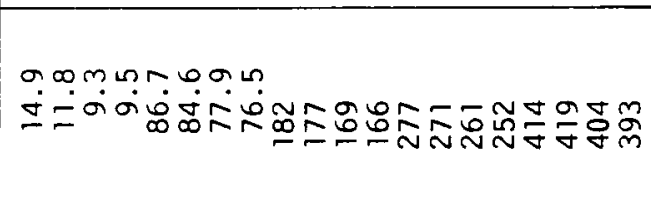 \\
\hline 苔 & 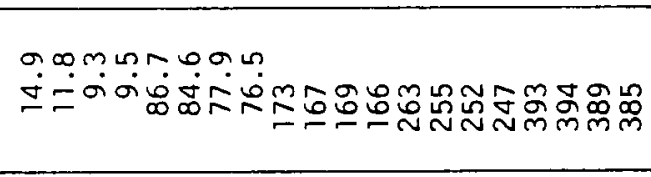 \\
\hline 年 & 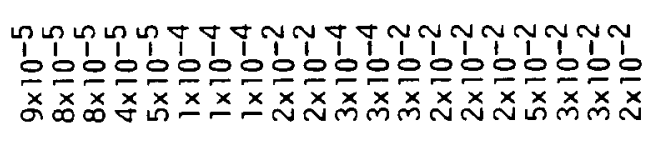 \\
\hline \begin{tabular}{l|l}
$u$ \\
0
\end{tabular} & 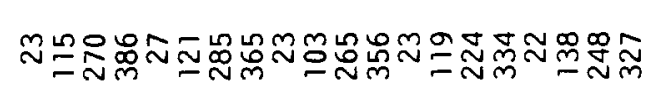 \\
\hline 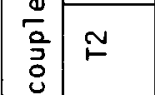 & ఇ \\
\hline 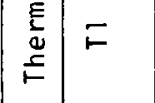 & 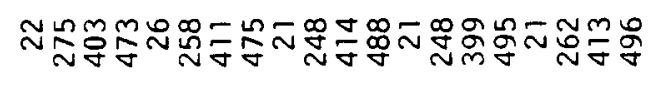 \\
\hline$\sum_{\bar{\nu}}^{n}$ & 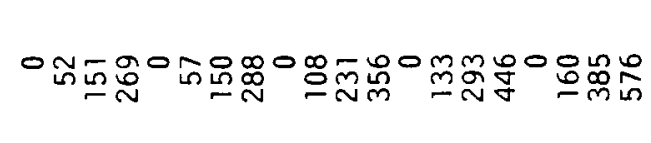 \\
\hline 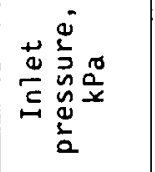 & 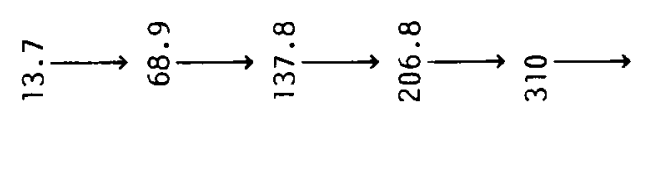 \\
\hline 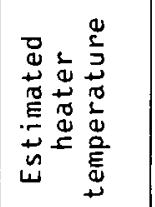 & 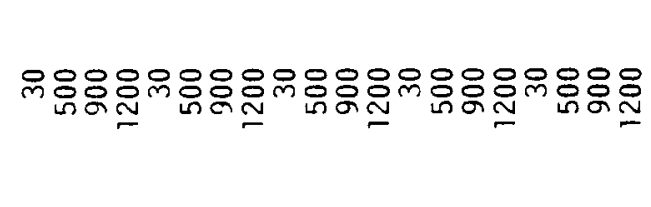 \\
\hline
\end{tabular}


TABLE IV. - SPECIFIC IMPULSE CORRELATION FACTORS

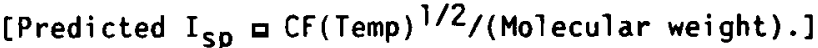

\begin{tabular}{|c|c|c|c|c|c|}
\hline \multirow[t]{2}{*}{ Gas } & \multicolumn{2}{|c|}{ Temperature, } & \multirow{2}{*}{$\begin{array}{l}\text { Correlation } \\
\text { factor-CF }\end{array}$} & \multirow{2}{*}{$\begin{array}{c}\text { Calculated } \\
\text { Isp' } \\
\text { seg }\end{array}$} & \multirow{2}{*}{$\begin{array}{l}\text { Measured } \\
\text { I sp' } \\
\text { sę }\end{array}$} \\
\hline & ${ }^{\circ} \mathrm{C}$ & K & & & \\
\hline Argon & $\begin{array}{r}30 \\
500 \\
900 \\
1200\end{array}$ & $\begin{array}{r}303 \\
773 \\
1173 \\
1473\end{array}$ & 124 & $\begin{array}{r}54 \\
86 \\
106 \\
119\end{array}$ & $\begin{array}{r}55 \\
87 \\
105 \\
117\end{array}$ \\
\hline $\begin{array}{l}\text { Carbon } \\
\quad \text { dioxide }\end{array}$ & $\begin{array}{r}30 \\
500 \\
900 \\
1200\end{array}$ & & 160 & $\begin{array}{r}63 \\
101 \\
124 \\
139\end{array}$ & $\begin{array}{r}65 \\
96 \\
122 \\
137\end{array}$ \\
\hline Nitrogen & $\begin{array}{r}30 \\
500 \\
900 \\
1200\end{array}$ & & 113 & $\begin{array}{r}70 \\
112 \\
138 \\
154\end{array}$ & $\begin{array}{r}74 \\
111 \\
139 \\
154\end{array}$ \\
\hline Hydrogen & $\begin{array}{r}30 \\
500 \\
900 \\
1200\end{array}$ & & 31 & $\begin{array}{l}269 \\
430 \\
530 \\
594\end{array}$ & $\begin{array}{l}281 \\
\overline{510} \\
583\end{array}$ \\
\hline
\end{tabular}

TABLE V. - SUMMARY OF RESPONSE TIMES FOR TRANSIENT INVESTIGATION

\begin{tabular}{|c|c|c|c|c|c|c|c|}
\hline Gas & $\begin{array}{c}\text { Heater } \\
\text { temperature, } \\
{ }^{\circ} \mathrm{C}\end{array}$ & $\begin{array}{c}\text { Inlet } \\
\text { pressure, } \\
\text { kPa }\end{array}$ & $\begin{array}{l}\text { Preheat } \\
\text { method }\end{array}$ & $\begin{array}{l}90 \% \\
\text { heater, } \\
\text { minimum }\end{array}$ & $\begin{array}{l}98 \% \\
\text { heater, } \\
\text { minimum }\end{array}$ & $\begin{array}{c}90 \% \\
I_{s p} \\
\text { minimum }\end{array}$ & $\begin{array}{c}98 \% \\
I_{s p} \\
\text { minimum }\end{array}$ \\
\hline $\begin{array}{l}\text { Argona } \\
\text { Argon } \\
\text { Argon } \\
\text { Argon } \\
\text { Argon } \\
\text { Argon } \\
\text { Argon } b \\
\text { Argon } \\
\text { Argon }, d \\
\text { Argon } \\
\text { Argone }\end{array}$ & $\begin{array}{r}760 \\
760 \\
760 \\
1200 \\
1200 \\
760 \\
760 \\
760 \\
760 \\
1200 \\
1200\end{array}$ & $\begin{array}{r}137.8 \\
68.9 \\
206.8 \\
68.9 \\
137.8 \\
68.9 \\
137.8 \\
206.8 \\
206.8 \\
137.8 \\
68.9\end{array}$ & $\begin{array}{l}\text { Slow } \\
\text { Slow } \\
\text { Slow } \\
\text { Slow } \\
\text { Slow } \\
\text { Fast } \\
\text { Fast } \\
\text { Fast } \\
\text { Fast } \\
\text { Fast } \\
\text { Fast }\end{array}$ & $\begin{array}{l}70 \\
-4 \\
45 \\
65 \\
50 \\
25 \\
12 \\
25 \\
7 \\
25 \\
40\end{array}$ & $\begin{array}{r}100 \\
65 \\
60 \\
75 \\
60 \\
45 \\
20 \\
40 \\
20 \\
45 \\
60\end{array}$ & $\begin{array}{l}42 \\
35 \\
30 \\
40 \\
25 \\
13 \\
12 \\
12 \\
7 \\
10 \\
15\end{array}$ & $\begin{array}{l}80 \\
55 \\
60 \\
60 \\
40 \\
40 \\
23 \\
35 \\
25 \\
25 \\
60\end{array}$ \\
\hline $\begin{array}{l}\text { Hydrogen } \\
\text { Hydrogen } \\
\text { Hydrogen } \mathrm{c} \\
\text { Hydrogen } \\
\text { Hydrogend } \\
\text { Hydrogen } \\
\text { Hydrogen } \\
\text { Hydrogen } \\
\text { Hydrogen }\end{array}$ & $\begin{array}{r}760 \\
760 \\
760 \\
1200 \\
1200 \\
760 \\
760 \\
1200 \\
1200\end{array}$ & $\begin{array}{r}68.9 \\
137.8 \\
137.8 \\
68.9 \\
68.9 \\
137.8 \\
68.9 \\
68.9 \\
137.8\end{array}$ & $\begin{array}{l}\text { Slow } \\
\text { Slow } \\
\text { Slow } \\
\text { Slow } \\
\text { Slow } \\
\text { Fast } \\
\text { Fast } \\
\text { Fast } \\
\text { Fast }\end{array}$ & $\begin{array}{r}65 \\
15 \\
18 \\
55 \\
13 \\
6 \\
7 \\
12 \\
13\end{array}$ & $\begin{array}{l}90 \\
40 \\
45 \\
80 \\
16 \\
10 \\
30 \\
60 \\
35\end{array}$ & $\begin{array}{r}40 \\
20 \\
13 \\
30 \\
15 \\
8 \\
8 \\
9 \\
10\end{array}$ & $\begin{array}{l}90 \\
40 \\
40 \\
60 \\
25 \\
10 \\
25 \\
25 \\
20\end{array}$ \\
\hline
\end{tabular}

amproper current level, too low.

bimproper current level and length, too high.

CImproper flow rate, too low.

Improper preheat period, too long.

eImproper preheat period, too short. 


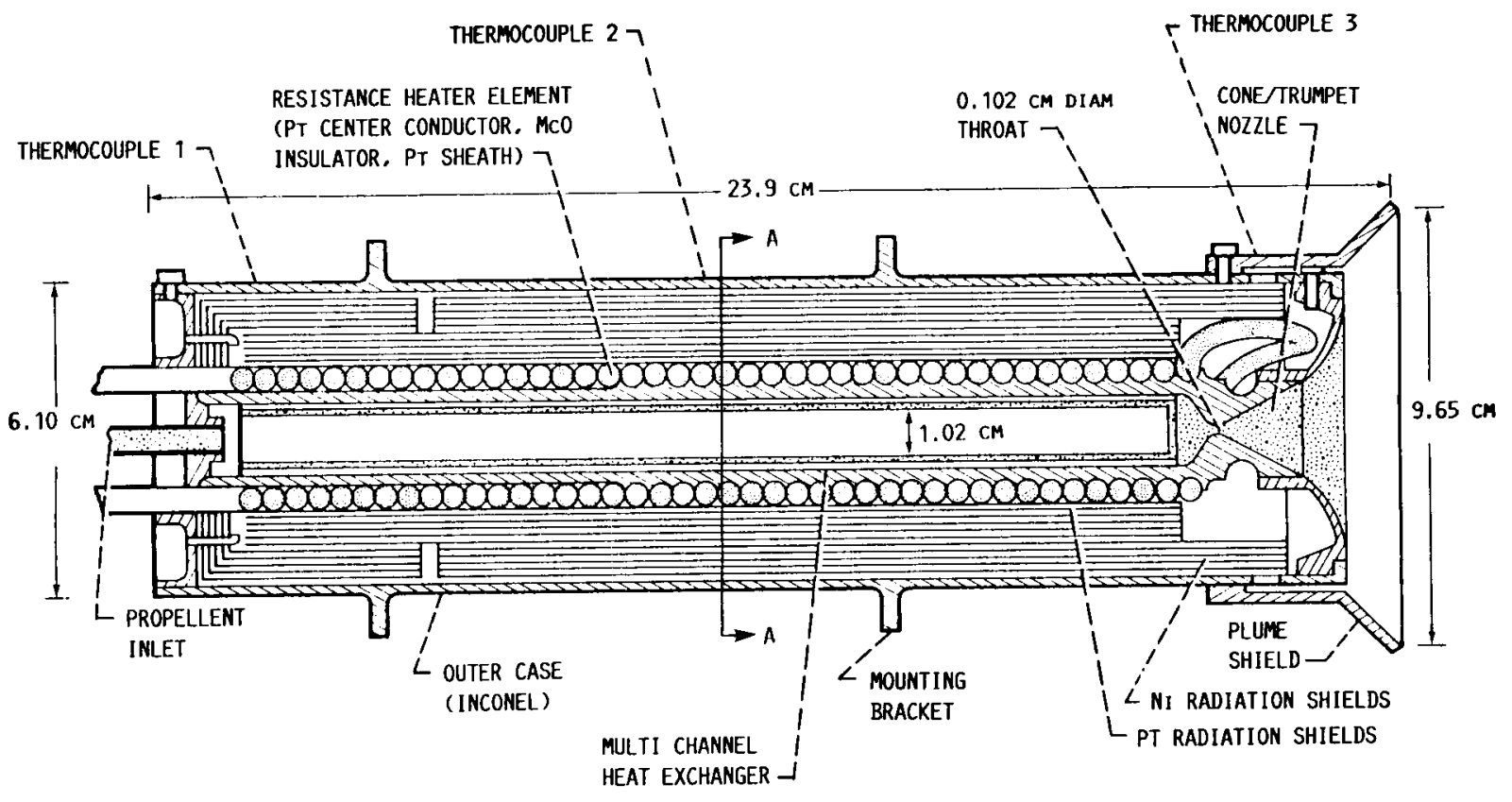

FIGURE 1. - AdVANCEd DEVELOPMENT ENGINEERING MODEL RESISTOJET AND THERMOCOUPLE LOCATION.

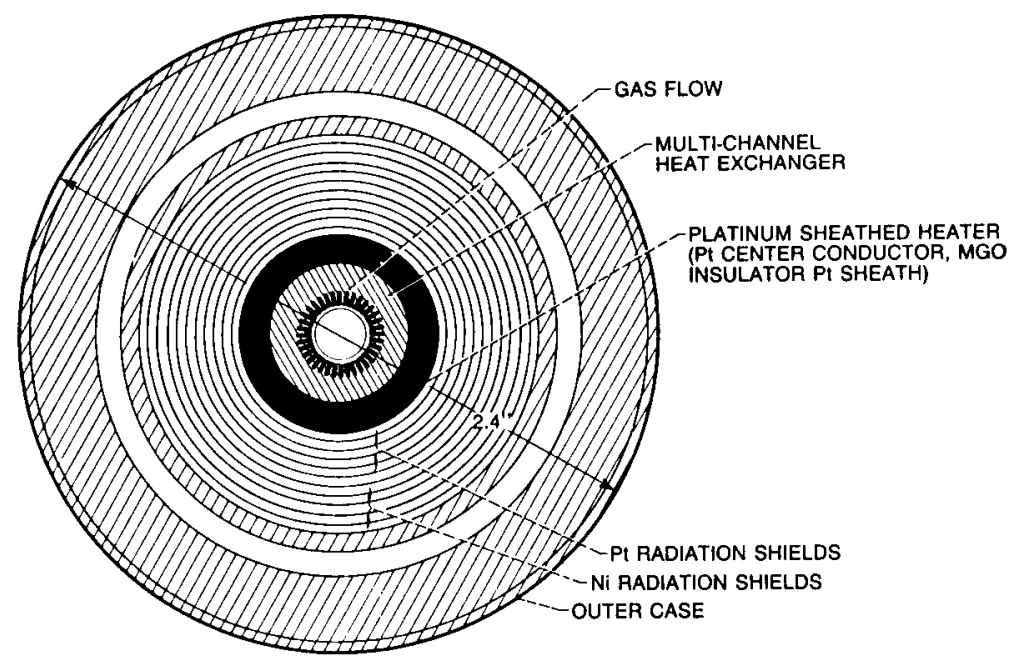

FIGURE 2. - ENGIMEERING HODEL RESISTOJET CROSS SECTION A-A. 


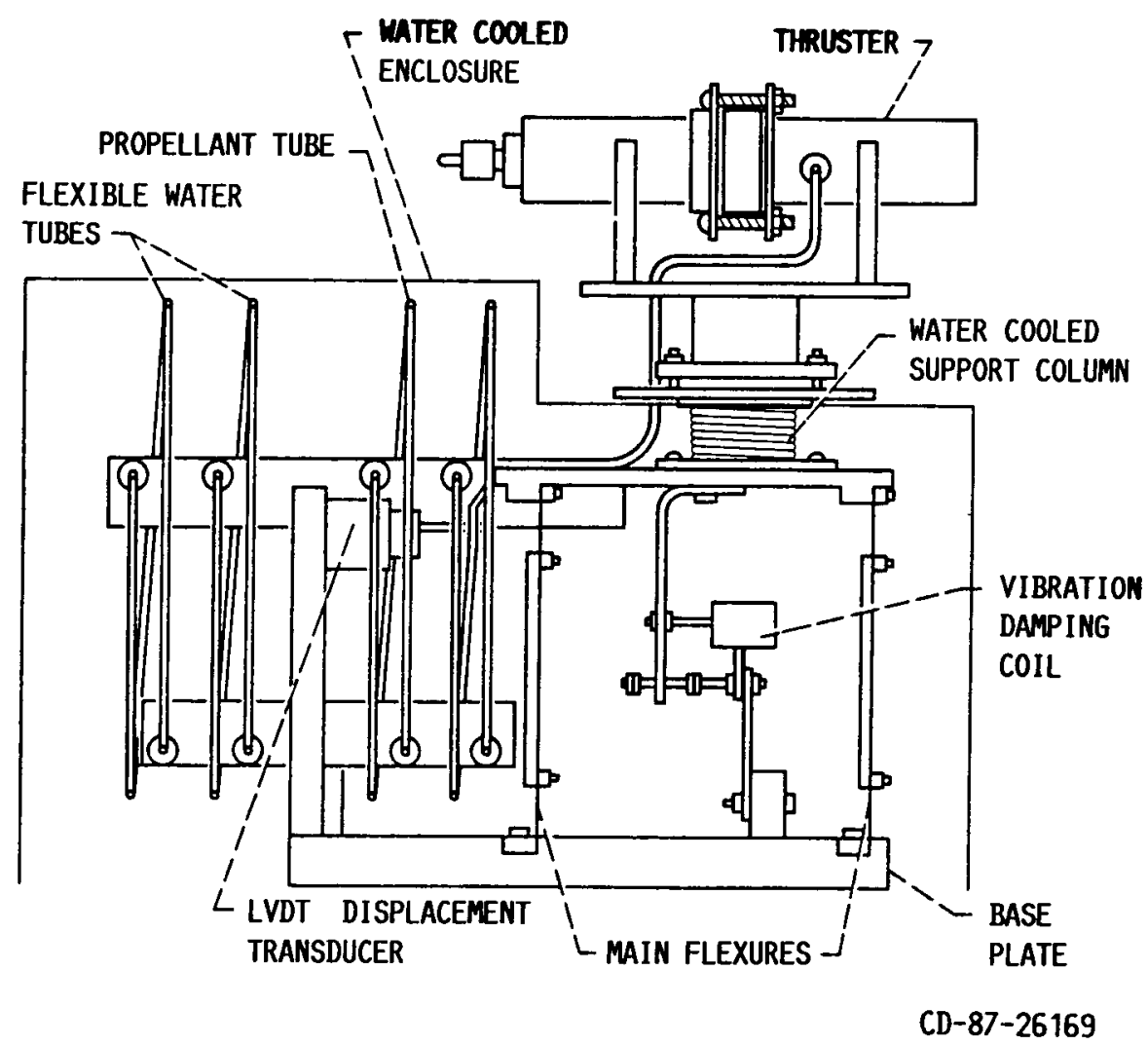

FIGURE 3. - SCHEMATIC DIAGRAM OF THRUST STAND WITH THRUSTER MOUNTED.

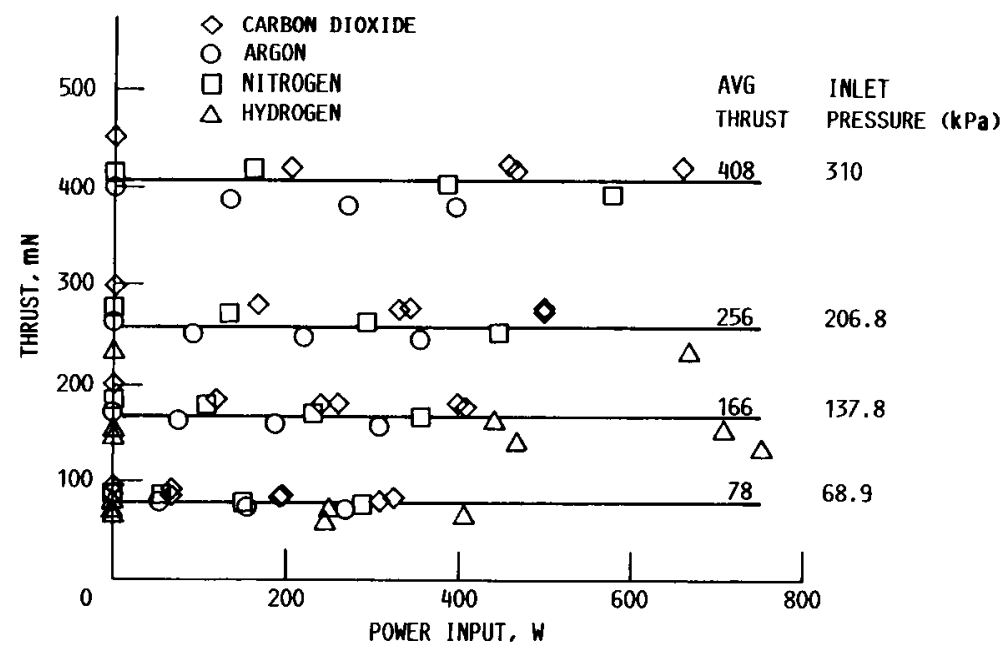

FIGURE 4. - CORRECTED THRUST AS A FUNCTION OF POWER INPUT FOR INLET PRESSURES OF 68.9 TO $310 \mathrm{kPa}$. 

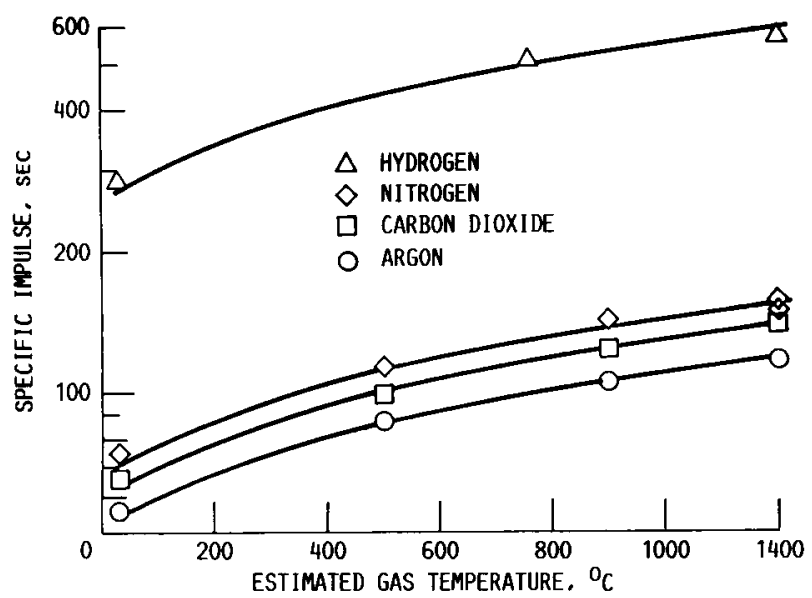

FIGURE 5. - SPECIFIC IMPULSE RELATIVE TO GAS TEMPERATURE FOR INLET PRESSURES OF 68.9 TO $310 \mathrm{kPa}$.

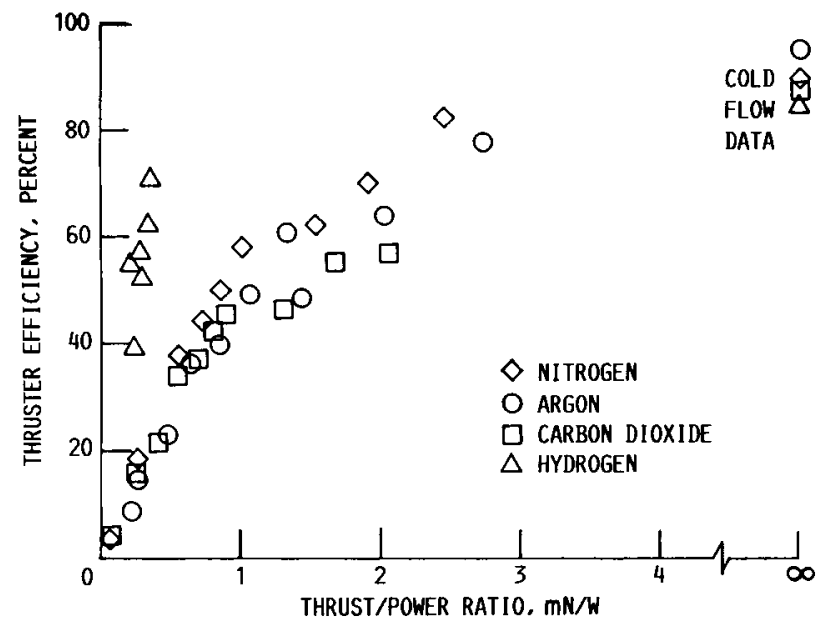

FIGURE 7. - OVERALL THRUSTER EFFICIENCY FOR ENTIRE

TEST MATRIX RELATIVE TO THE THRUST TO POWER RATIO.

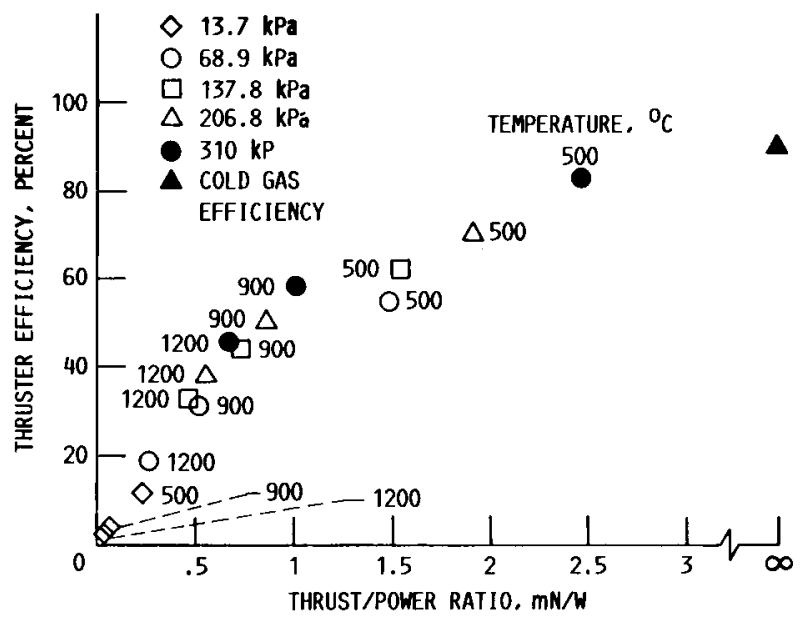

HIGURE 6. - OVERALL THRUSTER EFFICIENCY RELATIVE TO POWER RATIO FOR NITROGEN.

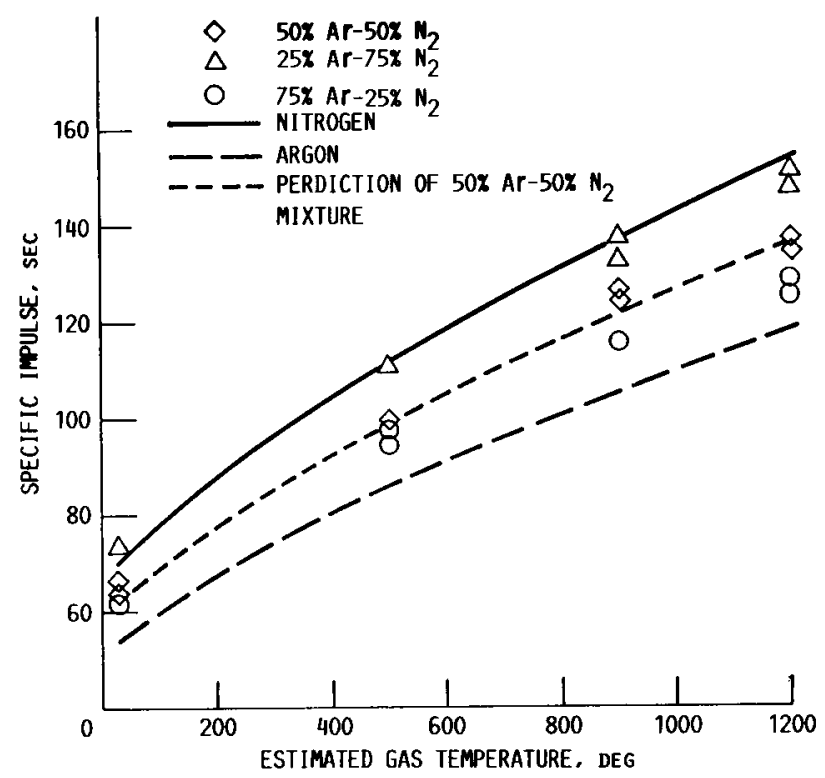

FIGURE 8. - SPECIFIC IMPULSE RELATIVE TO GAS TEMPERATURE FOR VARIOUS MIXTURES OF ARGOW AND NITROGEN. 


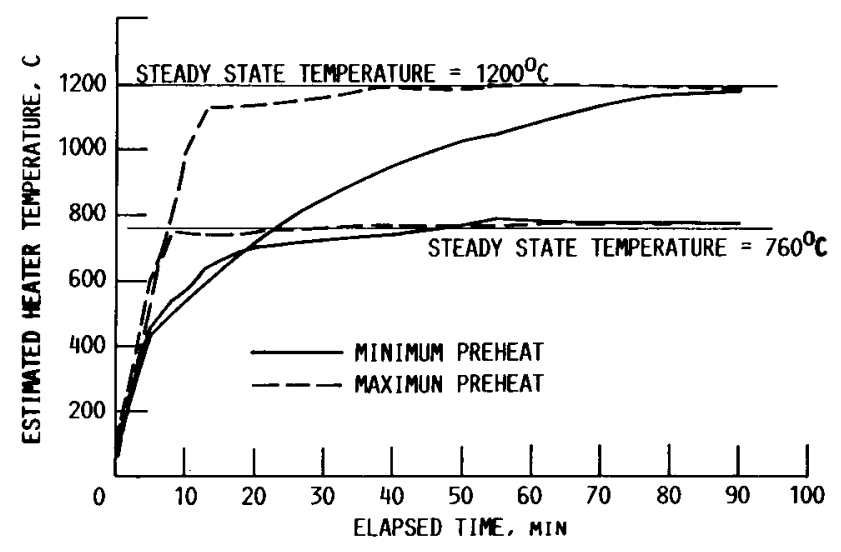

FIGURE 9. - TYPICAL HEATER TEMPERATURE TRANSIENT RESPONSE TINE USING HYDROGEM GAS.

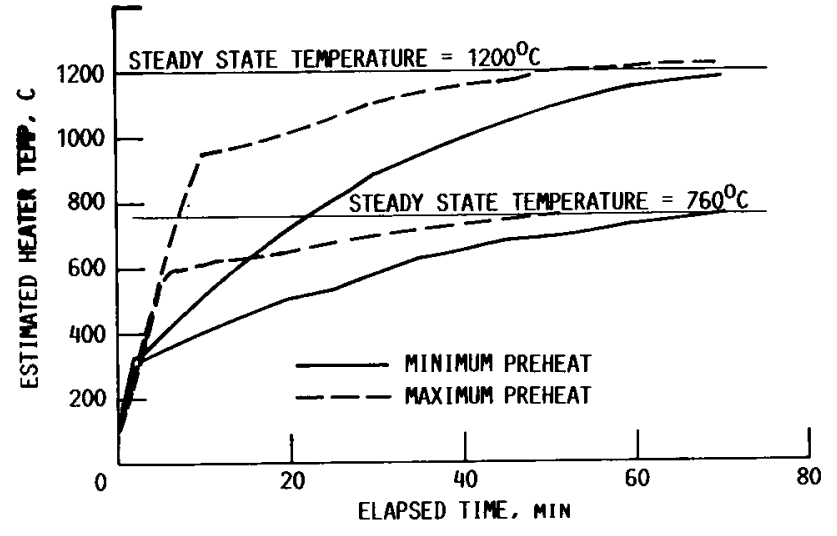

FIGURE 10. - TYPICAL HEATER TEMPERATURE TRANSIENT RESPOUSE TIFE USING ARGOW GAS.

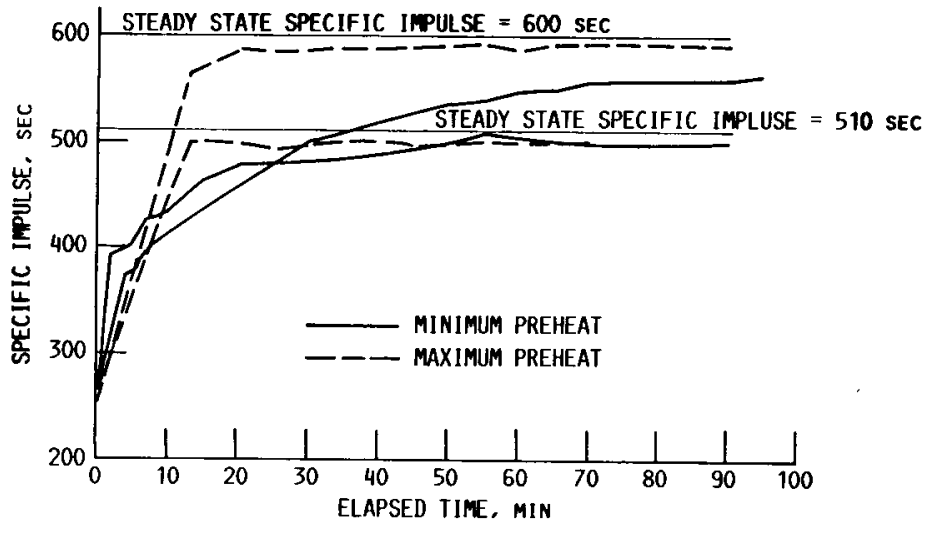

FIGURE 11. - TYPICAL TRANSIENT RESPONSE CHARACTERISTICS OF SPECIFIF IMPULSE WITH HYDROGEN.

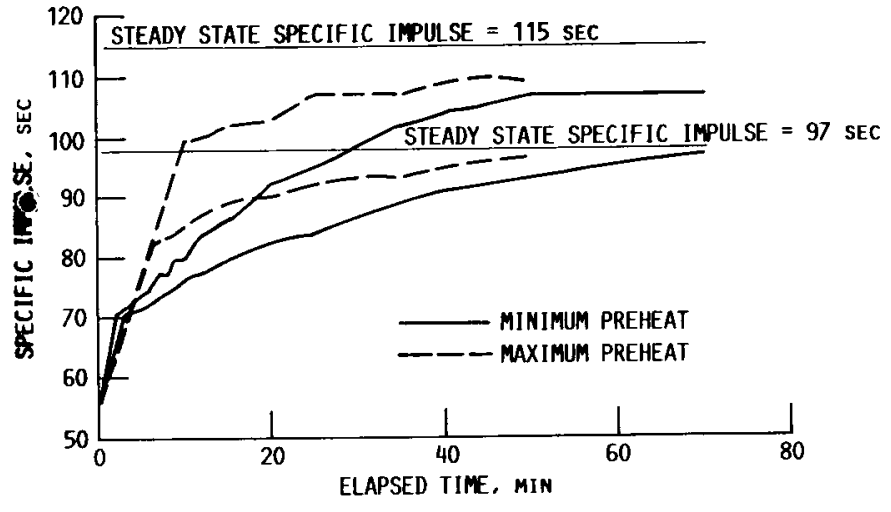

FIGURE 12. - TYPICAL TRANSIENT RESPONSE CHARACTERISTICS OF SPECIFIC IMPULSE WITH ARGOW. 


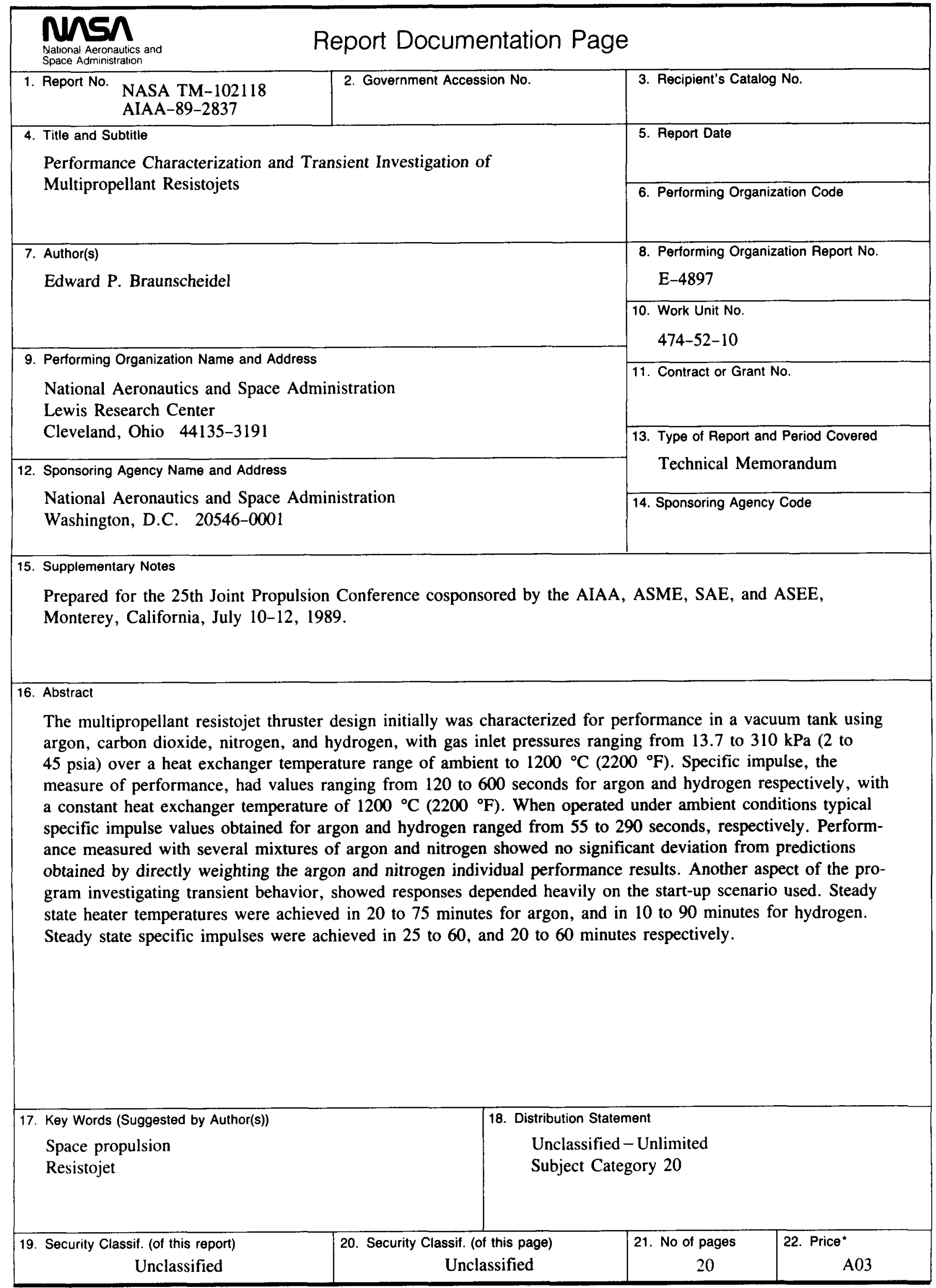

